\title{
IMPLEMENTASI KELAIKLAUTAN KAPAL PADA ARMADA YANG BERBASIS DI PELABUHAN PERIKANAN SAMUDRA (PPS) KUTARAJA
}

\author{
Analysis of the Implementation Level of Ship's Seaworthiness Based On PPS Kutaraja \\ Oleh: \\ Zakyatul Muna $^{1}$, Fis Purwangka ${ }^{2 *}$, Wazir Mawardi ${ }^{2}$ \\ ${ }^{1}$ Program Studi Teknologi Perikanan Laut Pascasarjana IPB, \\ Bogor, Indonesia \\ ${ }^{2}$ Departemen Pemanfaatan Sumberdaya Perikanan FPIK-IPB, Bogor, \\ Indonesia \\ *Korespondensi penulis: fis@psp-ipb.org
}

\begin{abstract}
ABSTRAK
Kelaiklautan kapal merupakan salah satu syarat yang wajib dipenuhi oleh kapal pada setiap aktivitas pelayaran, begitupun juga keselamatan dan keamanan kapal ditandai dengan kondisi terpenuhinya persyaratan kelaiklautan kapal. BASARNAS Aceh (2019) membuktikan kasus kecelakaan kapal di Provinsi Aceh mengalami peningkatan, pada tahun 2018 sebanyak 22 kasus meningkat menjadi 36 kasus pada tahun 2019. Kecelakaan ini dipicu karena adanya indikasi pengabaian aspek keselamatan dalam berlayar. Tujuan penelitian yaitu menentukan tingkat implementasi kelaiklautan kapal pada armada kapal penangkap ikan yang berbasis di PPS Kutaraja. Penelitian ini dilaksanakan pada bulan Februari 2021 di PPS Kutaraja, Kota Banda Aceh. Metode yang digunakan dalam penelitian ini adalah studi kasus. Metode pengumpulan data dilakukan dengan metode wawancara (kuesioner) dan pengamatan langsung di lapangan. Teknik pengambilan sampel yang digunakan ada 3 yaitu purposive sampling, proportionate stratified random sampling dan accidental sampling. Berdasarkan pengolahan data, didapatkan hasil penelitian berikut: penerapan aspek kelaiklautan kapal yang berbasis di PPS Kutaraja berdasarkan aspek keselamatan, pencegahan pencemaran perairan dari kapal, pengawakan kapal, kesejahteraan awak kapal dan kesehatan penumpang, status hukum kapal, manajemen dan kesehatan penumpang serta kelengkapan surat dan dokumen masing-masing memiliki persentase skoring sebesar 43,32\% (sangat baik), 98,31\% (sangat buruk), 65,15\% (baik), 79,38\% (ada), 82,39 \% (ada), 57,27\% (sangat baik), dan 59,09\% (ada).
\end{abstract}

Kata kunci: kapal perikanan, kelaiklautan kapal, keselamatan pelayaran, laik laut

\section{ABSTRACT}

Ship's seaworthiness is one of the requirements must be met by ships in every shipping activity, as well as ship safety and security is marked by the condition of fulfilling ship's seaworthiness. BASARNAS Aceh (2019) proves that cases of ship accidents in Aceh increased, in 2018 as many as 22 cases increased to 36 cases in 2019. This accident was triggered due to indications of neglect of the safety aspect in sailing. The purpose of this research is to determine the level of implementation of ship seaworthiness in fishing vessels based in PPS Kutaraja. This research was conducted in February 2021 at PPS Kutaraja.The method of data collection was done by interview method and observation. There are 3 sampling techniques used, are purposive sampling, proportionate stratified random sampling and accidental sampling. Based on data processing, the following research results were obtained: the application of aspects of seaworthiness based at PPS Kutaraja based on safety aspects, prevention of water pollution from ships, ship manning, welfare of ship crews and passenger health, legal status of ships, management and health of passengers and completeness of letters and documents. each document has a scoring percentage of $43.32 \%$ (very 
good), $98.31 \%$ (very bad), 65.15\% (good), $79.38 \%$ (exist), $82.39 \%$ (exist), $57.27 \%$ (very good), and $59.09 \%$ (exist).

Key words: fishing vessels, maritime safety, seaworthiness ship, seaworthy

\section{PENDAHULUAN}

Pekerjaan di atas kapal merupakan pekerjaan yang tergolong membahayakan, statistik Food Agriculture Organization (FAO) memperkirakan pada tahun 2018 terdapat 59,51 juta orang terlibat dalam sektor utama perikanan tangkap dan akuakultur, dimana 20,5 juta orang mewakili akuakultur dan 39,0 juta orang terlibat dalam perikanan tangkap dengan jumlah total armada kapal penangkap ikan di dunia diperkirakan sekitar 4,56 juta (FAO 2020). International Labour Organisation (ILO) memperkirakan setiap tahun terdapat 2,78 juta pekerja yang tewas karena kecelakaan di tempat kerja atau penyakit terkait pekerjaan (ILO 2019). Laporan hasil investigasi Komite Nasional Keselamatan Transportasi (KNKT) menggambarkan pada kurun waktu 2015-2019 telah terjadi kecelakaan kapal seperti tenggelam, tubrukan, kandas dan terbakar di wilayah perairan Indonesia.

Jumlah kecelakaan ini 124 kasus dengan korban meninggal/hilang sebanyak 579 orang dan korban luka-luka sebanyak 41 dari total korban jiwa mencapai 620 orang. Jumlah kasus kecelakaan kapal merupakan salah satu indikasi perlu perbaikan dalam sistem transportasi laut, sehingga perlu adanya persyaratan yang dipenuhi oleh kapal agar kapal memenuhi kelayakan untuk berlayar. Kelaiklautan kapal merupakan salah satu syarat yang wajib terpenuhi dalam aktivitas pelayaran guna keselamatan dan keamanan di atas kapal. Menurut Undang-Undang Republik Indonesia nomor 17 tahun 2008 tentang pelayaran, kelaiklautan kapal adalah keadaan kapal yang memenuhi persyaratan keselamatan kapal, pencegahan pencemaran perairan dari kapal, pengawakan, garis muat, pemuatan, kesejahteraan awak kapal dan kesehatan penumpang, status hukum kapal, manajemen keselamatan dan pencegahan pencemaran dari kapal, dan manajemen keamanan kapal untuk berlayar di perairan tertentu.

Angka kecelakaan kapal di Aceh cenderung meningkat. BASARNAS Aceh (2019) membuktikan kasus kecelakaan kapal di Provinsi Aceh mengalami peningkatan dari tahun 2018-2019 baik untuk kapal penangkap ikan, kargo maupun kapal penumpang. Total kecelakaan kapal pada tahun 2019 mengalami peningkatan kasus dari sebanyak 22 kasus pada tahun 2018 menjadi 36 kasus pada tahun 2019. Kecelakaan ini dipicu karena adanya indikasi pengabaian aspek keselamatan dalam berlayar. Adapun beberapa faktor yang diduga berkontribusi dalam kecelakaan kapal ialah human error, teknis dan cuaca (Rahman et al. 2015). Jika hal ini tidak diperhatikan, maka kecelakaan akan terus terjadi dan aktivitas pelayaran akan selalu penuh dengan risiko. Kecelakaan kapal banyak terjadi karena kapal tidak memenuhi kelaiklautan kapal (Rahman et al. 2015). Menurut Mudiyanto (2019) kelaiklautan kapal memiliki hubungan yang kuat terhadap keselamatan pelayaran sehingga kelaiklautan di atas kapal harus ditingkatkan untuk menunjang keselamatan pelayaran. Oleh karena itu, informasi tentang tingkat penerapan aspek kelaiklautan kapal menjadi sangat penting guna menurunkan risiko kecelakaan pelayaran.

Penelitian ini dilakukan di PPS Kutaraja dengan beberapa pertimbangan yaitu peningkatan jumlah armada, dimensi kapal bervariasi, dan satu-satunya Pelabuhan Perikanan Samudera (PPS) yang ada di Aceh, alasan inilah yang menjadikan PPS Kutaraja layak dijadikan sebagai tempat studi kasus penelitian terkait tingkat implementasi kelaiklautan kapal. Adapun tujuan dari penelitian ini yaitu menetukan tingkat implementasi kelaiklautan kapal pada armada kapal penangkap ikan yang berbasis di PPS Kutaraja. Aspek yang akan dianalisis untuk mencapai tujuan penelitian ialah aspek keselamatan kapal, pencegahan pencemaran perairan dari kapal, pengawakan kapal, kesejahteraan awak kapal dan kesehatan penumpang, status hukum kapal, serta manajemen keselamatan dan keamanan kapal. 


\section{METODE PENELITIAN}

Penelitian ini dilaksanakan pada bulan Februari 2021 yang berlokasi di PPS Kutaraja, Kota Banda Aceh Provinsi Aceh. Metode yang digunakan dalam penelitian ini adalah studi kasus yang berbasis di PPS Kutaraja. Metode pengumpulan data dilakukan dengan metode wawancara mengikuti panduan kuesioner dan pengamatan langsung di lapangan. Teknik pengambilan sampel yang digunakan ada tiga teknik yaitu purposive sampling, proportionate stratified random sampling dan accidental sampling. Purposive sampling yaitu teknik penentuan responden didasarkan pada pertimbangan peneliti (Nasution 2013). Kriteria responden yang diambil diantaranya pihak yang bertanggung jawab terhadap tugas pemeriksaan kelaiklautan kapal, petugas yang mengeluarkan dokumen kapal serta nelayan (nahkoda). Responden terdiri atas syahbandar, panglima laot lhok, pengelola PPS Kutaraja dan nelayan (nahkoda). Teknik proportionate stratified random sampling digunakan untuk teknik penentuan jumlah kapal. Teknik proportionate stratified random sampling digunakan pada penelitian ini karena populasi kapal tidak homogen dan berstrata secara proporsional (Sugiyono 2011). Strata yang dimaksudkan dalam penelitian ini yaitu variasi kategori ukuran kapal (lihat Tabel 1). Jumlah total anggota sampel ditentukan melalui rumus Taro Yaname dan Slovin dalam Riduwan dan Kuncoro (2011) dimana teknik pengambilan sampel dapat menggunakan rumus dari Taro Yaname dan Slovin apabila populasi sudah diketahui. Adapun rumus tersebut ialah sebagai berikut:

$$
n=\frac{N}{N d^{2}+1}
$$

Dimana:

$\mathrm{n} \quad$ = Jumlah anggota sampel;

$\mathrm{N}=$ Jumlah populasi; dan

$\mathrm{d}^{2} \quad=$ Presisi (presisi yang ditetapkan 10\%).

Maka jumlah anggota sampel berdasarkan populasi ialah 78 unit kapal. Jika jumlah anggota sampel telah diketahui, selanjutnya penentuan jumlah anggota sampel bertingkat (berstrata), dilakukan dengan cara pengambilan sampel secara proportional random sampling yaitu menggunakan rumus alokasi proporsional:

$$
n=\frac{N i}{N} n
$$

Dimana:

$\mathrm{ni} \quad=$ jumlah anggota sampel menurut stratum;

$\mathrm{N} \quad$ = jumlah anggota populasi seluruhnya;

$\mathrm{n} \quad=$ jumlah anggota sampel seluruhnya; dan

$\mathrm{Ni}=$ jumlah anggota populasi menurut stratum.

Jumlah total anggota sampel yang diambil per-kategori ukuran kapal ialah kapal ukuran 6-10 GT (24 unit), 11-20 GT (7 unit), 21-30 GT (14 unit), 31-50 GT (17 unit), 51-60 GT (13 unit), 61-100 GT (2 unit), dan $>100$ GT (1 unit). Kriteria kapal yang diteliti untuk penerapan aspek kelaiklautan kapal sebagai salah satu syarat untuk keselamatan ialah kapal yang berukuran $>7$ GT. Hal ini mengacu pada Undang-Undang nomor 17 tahun 2008 tentang pelayaran. Teknik accidental sampling adalah teknik penentuan sampel berdasarkan kebetulan, yaitu kapal yang secara kebetulan ditemui oleh peneliti di PPS Kutaraja dapat digunakan sebagai sampel jika kapal tersebut memenuhi kriteria. Adapun pengelompokkan data berdasarkan ukuran kapal pada Tabel 1. Analisis data yang digunakan untuk mencapai tujuan penelitian ialah analisis deskriptif. Adapun data yang akan dianalisis adalah hasil dari skoring penerapan aspek kelaiklautan kapal,sesuai dengan Undang-undang nomor 17 tahun 2008 tentang pelayaran. Penilaian menggunakan skala 1 s.d 4, yaitu: 1=sangat baik, 2=baik, 3=buruk dan $4=$ sangat buruk. Aspek kelaiklautan kapal dengan kriteria yang telah ditentukan tercantum pada Tabel 1. 
Tabel 1. Nilai skor penerapan aspek kelaiklautan kapal berdasarkan Undang-undang nomor 17 tahun 2008 tentang pelayaran

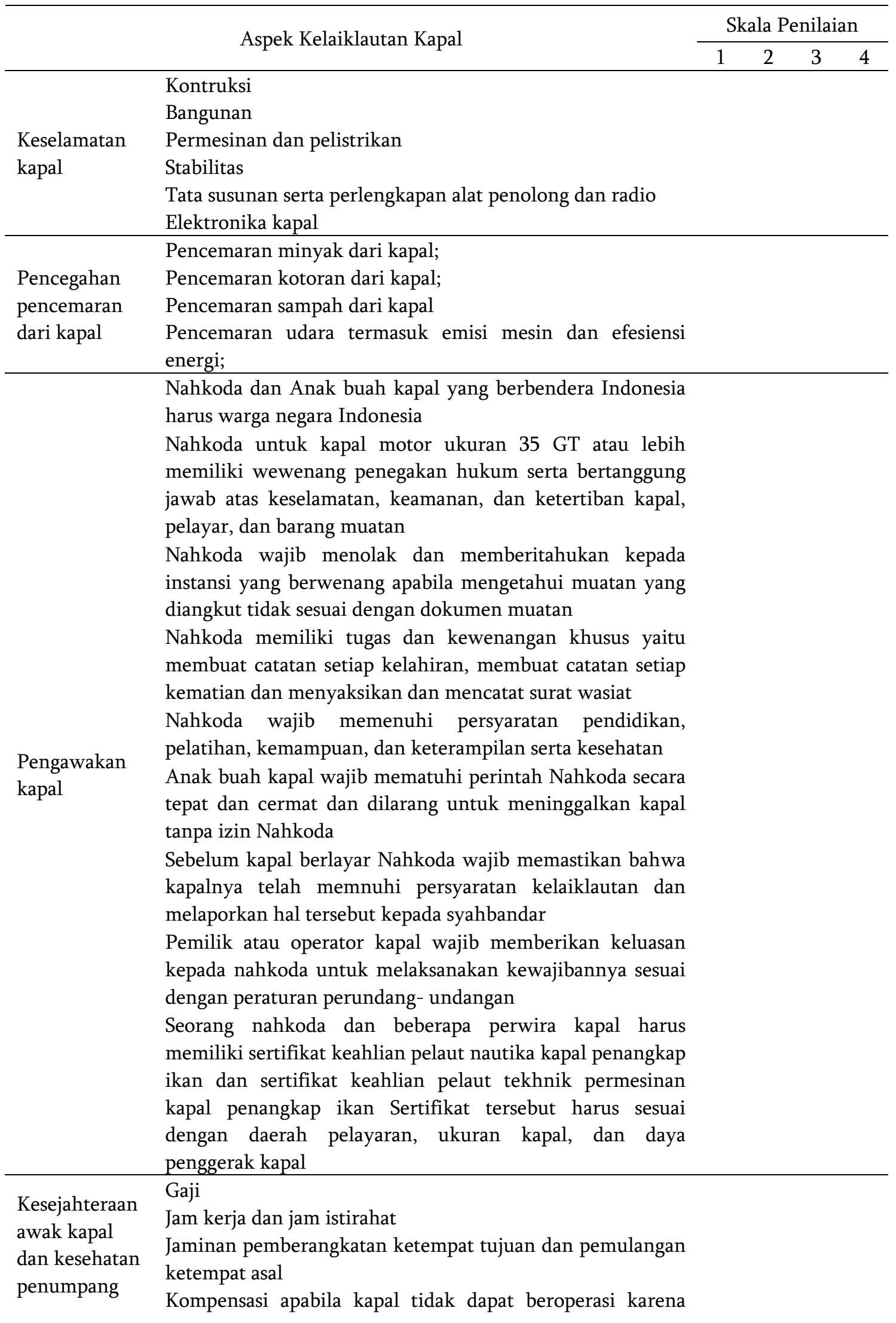




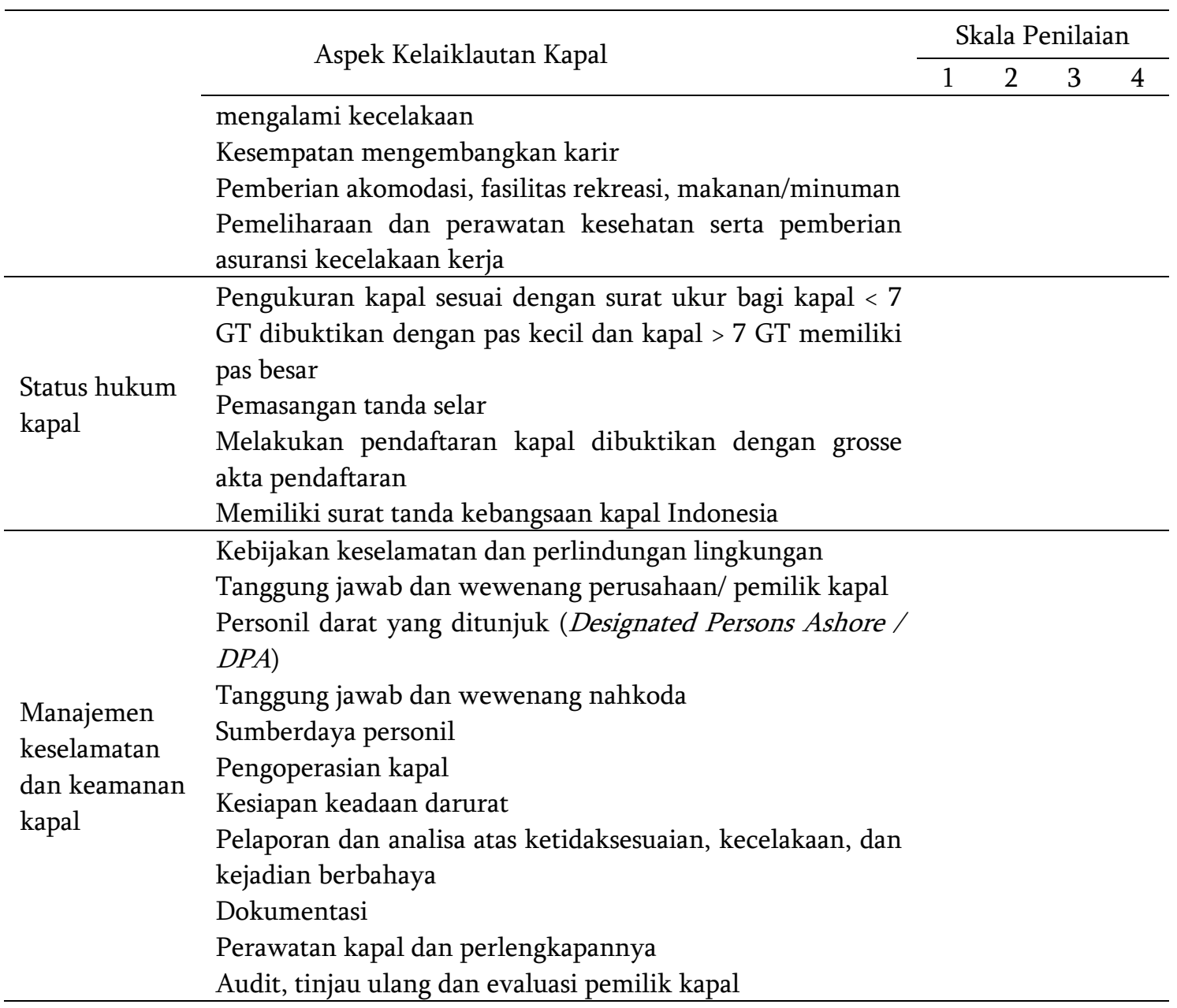

Hasil skoring dianalisis menggunakan analisis deskriptif untuk memberikan penjelasan dan gambaran tingkat penerapan kelaiklautan pada armada penangkap ikan di PPS Kutaraja.

\section{HASIL DAN PEMBAHASAN}

Kondisi kapal dinyatakan laik laut jika keadaan kapal telah memenuhi aspek kelaiklautan kapal meliputi aspek keselamatan kapal, pencegahan pencemaran perairan dari kapal, pengawakan, kesejahteraan awak kapal dan kesehatan penumpang, status hukum kapal, serta manajemen keselamatan dan keamanan kapal. Penentuan tingkat implementasi kelaiklautan kapal pada armada penangkap ikan yang berbasis di PPS Kutaraja dilakukan dengan skoring penerapan aspek kelaiklautan kapal, nilai skror diperoleh dari kuesioner yang telah disebar. Jumlah populasi kapal ialah 356 unit, adapun jumlah anggota sampel yang diambil berdasarkan total populasi ialah sebanyak 78 unit dengan tambahan cadangan sebanyak 10 unit, total sampel ialah 88 unit kapal.

\section{Keselamatan Kapal}

Kriteria aspek keselamatan menunjukkan 43,32 \% kapal mendapat nilai 1 (sangat baik) 7,53 \% memperoleh nilai 4 (sangat buruk) Gambar 1a. Pengadaan sosialisasi aspek keselamatan di atas kapal menjadi kriteria yang memperoleh nilai paling rendah, sebanyak 46 kapal mendapat nilai 4 (sangat buruk) dan hanya 25 kapal yang mendapat nilai 2 (baik) dan tidak ada kapal yang mendapat nilai 1 (sangat baik). Hal ini menunjukkan, kapal yang menerapkan sosialisasi tentang aspek keselamatan sangat rendah. Sedangkan perolehan nilai tertinggi yaitu kriteria pengadaan perangkat komunikasi radio kapal dan penempatan perangkat navigasi dan perangkat radio sesuai fungsi. Masing-masing 55 kapal mendapatkan nilai 1 (sangat baik). Hal ini membuktikan bahwa nelayan yang berbasis di PPS 
Kutaraja sudah membuka diri dengan baik untuk beradaptasi dengan teknologi guna memudahkan aktivitas mereka dan menunjang aktivitas keselamatan.

Namun tidak dengan jenis kapal one day fishing, mereka beranggapan jarak tempuh daerah penangkapan ikan tidak jauh dari pelabuhan fishing base sehingga cukup mengandalkan handphone sebagai alat komunikasi mereka di darat-laut. Padahal idealnya sistem navigasi dan komunikasi ialah ketika informasi tidak terputus dan menggunakan perangkat nirkabel dengan spektrum frekuensi radio sebagai mediumnya sehingga perolehan informasi lebih fleksibel (Wahab 2014). Keberadaan navigasi dan keberlangsungan komunikasi antarpelaku aktivitas perikanan darat-darat maupun daratlaut menjadi penentu keberhasilan aktivitas perikanan. Oleh karena itu, sudah sepatutnya sistem navigasi dan komunikasi dikembangkan oleh pihak PPS Kutaraja.

Hasil skoring kriteria aspek keselamatan menggunakan skala penilaian 0 (tidak ada) dan 1 (ada). 85,74 \% kapal memperoleh nilai 1 (ada), hanya 14,26\% yang mendapat penilaian 0 (tidak ada) (Gambar 1b), yang termasuk 14,26\% ialah sebanyak 23 kapal tidak memiliki sekat buritan dan sebanyak 88 kapal tidak memiliki dokumen informasi stabilitas kapal. Kapal yang tidak memiliki sekat buritan tersebut ialah kategori kapal berkisar antara 6-12 GT dikarenakan berukuran relatif lebih kecil sehingga penyekatan ruang kapal terbatas. Pembagian sekat dalam kontruksi bangunan kapal selain berfungsi sebagai dinding pemisah juga berfungsi sebagai cadangan apung apabila kapal mengalami kebocoran disalah satu ruangan (Nur 2015).

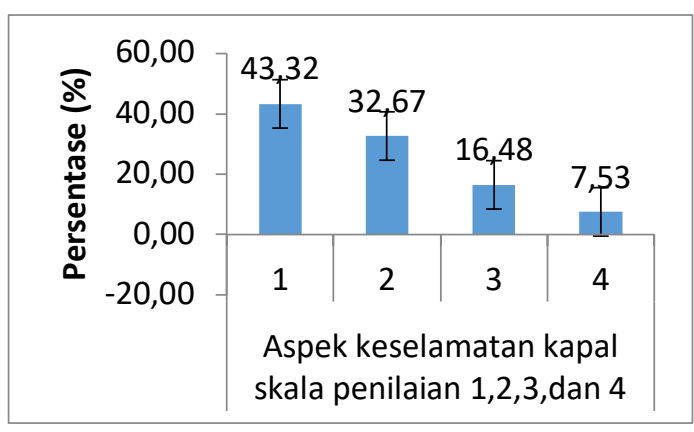

A

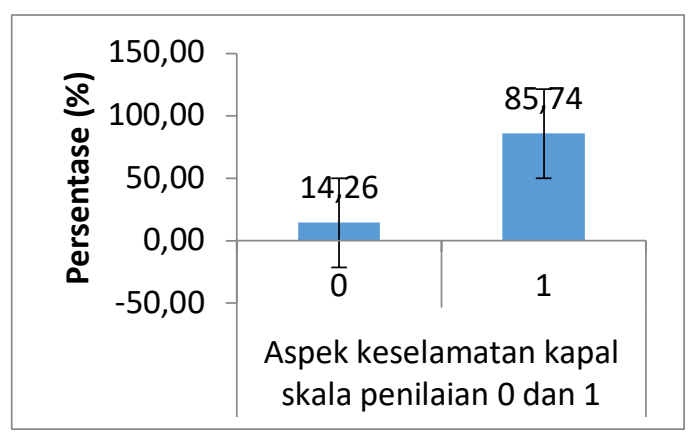

B

Gambar 1 (a) Skoring aspek keselamatan kapal (b) Skoring aspek keselamatan kapal

Pada umumnya, kapal 6-12 GT yang berbasis di PPS Kutaraja tidak memiliki ruang mesin. Mesin tempel yang digunakan untuk menggerakkan kapal diletakkan di bawah dek kapal tepat di ruang kemudi. Oleh sebab itu, tidak adanya penyekatan buritan pada kapal ukuran tersebut. Kapal yang berbasis di PPS Kutaraja tidak memiliki dokumen informasi stabilitas kapal. Informasi stabilitas ini berguna untuk nahkoda dalam menentukan keadaan pemuatan yang layak pada setiap kondisi kapal. Pihak syahbandar menyebutkan bahwa dokumen informasi stabilitas tidak menjadi dokumen wajib yang harus dimiliki oleh pemilik kapal, mempertimbangkan pembuatan kapal yang dibuat di galangan tradisional sehingga tidak adanya informasi stabilitas kapal yang dikeluarkan oleh pihak galangan.

\section{Pencegahan Pencemaran Perairan dari Kapal}

Hasil skoring kriteria aspek pencegahan dan pencemaran perairan dari kapal dapat dilihat pada Gambar 2, menunjukkan aspek pencegahan pencemaran perairan dari kapal sangat buruk. Hal ini dapat dibuktikan berdasarkan hasil skoring, dimana 98,31 \% kapal mendapat nilai 4 (sangat buruk) dan 0,19\% kapal mendapat nilai 1 (sangat baik). Terdapat 5 unit kapal yang memiliki tempat penampungan sampah di atas kapal dan hanya 2 unit kapal yang pernah mengikuti sosialisasi pencegahan pencemaran yang diakibatkan oleh kapal. 


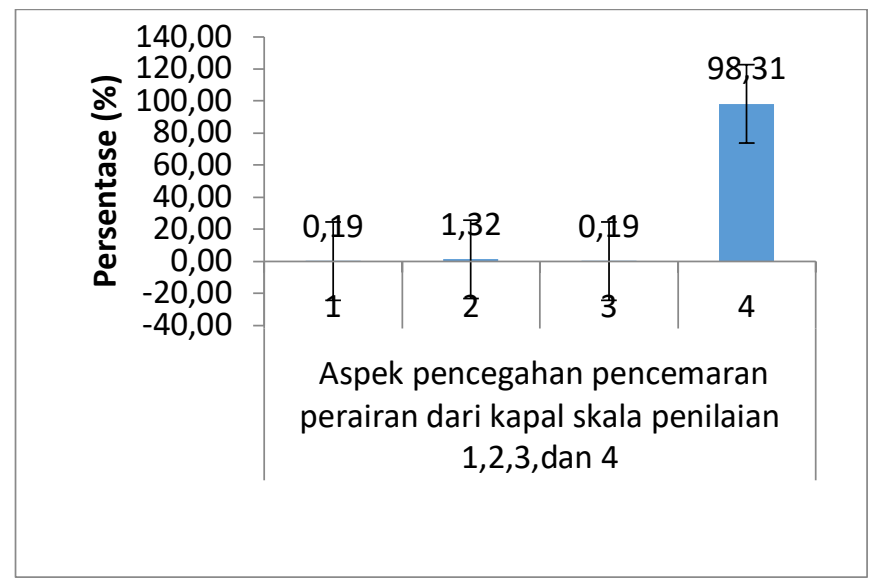

Gambar 2. Diagram skoring aspek pencegahan pencemaran perairan kapal

Hal ini mengindikasikan bahwa, kapal yang berbasis di PPS Kutaraja tidak menaruh kepedulian terhadap kebersihan lingkungan, juga tidak menaruh kepedulian terhadap pencegahan pencemaran perairan dari kapal. Kurangnya sosialisasi terkait pencegahan pencemaran perairan dari kapal kepada nelayan dapat menjadi salah satu faktor. Hal ini menjadi suatu masalah yang perlu diperhatikan oleh pihak PPS Kutaraja. Perlu adanya pengedukasian untuk nelayan terkait peraturan pencegahan pencemaran perairan dari kapal. Pencemaran perairan dari aktivitas kapal dapat menjadi ancaman terhadap lingkungan laut, oleh karena itu perlu adanya kerjasama dari berbagai pihak baik itu nelayan, pemerintah, masyarakat, panglima laot dan syahbandar untuk mewujudkan pencegahan.

\section{Pengawakan Kapal}

Kriteria pendidikan, pelatihan dan kemampuan serta kepemilikan sertifikat keahlian merupakan kriteria dari aspek pengawakan kapal yang harus dipenuhi oleh nahkoda dan masinis. Sebanyak 65,15\% memperoleh nilai 2 (baik); 16,67\% memperoleh nilai 1 (sangat baik); 17,80\% mendapat nilai 3 (buruk); dan 0,38\% mendapat nilai 4 (sangat buruk) (Gambar 3a). Jenjang pendidikan tidak menjadi syarat untuk dapat bekerja sebagai nelayan, bahkan nahkoda dan masinis itu sendiri bukan lulusan sekolah kemaritiman. Jenjang pendidikan nelayan yang berbasis di PPS Kutaraja mayoritas tamatan SD-SMP. Namun, keahlian melaut didapatkan langsung dari pengalaman melaut secara turun temurun. Skor untuk kriteria aspek pengawakan kapal lain yang harus dipenuhi dapat dilihat pada Gambar 3b, seluruh kriteria telah terpenuhi yaitu sebanyak 100\% memperoleh nilai 1 (ada).

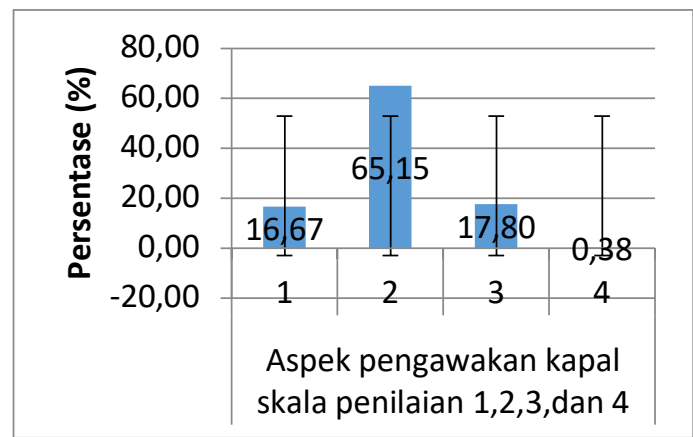

A

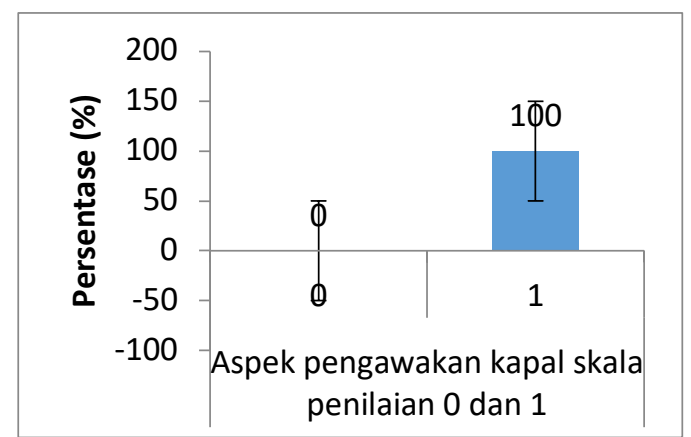

B

Gambar 3 (a) Skoring aspek pengawakan kapal (b) Skoring aspek pengawakan kapal

Hal ini menunjukkan bahwa nahkoda telah berkerja dengan baik dalam menerapkan aspek pengawakan kapal pada armada yang menjadi tanggung jawab mereka. Pengawakan menjadi salah satu hal penting dalam menjamin keselamatan pelayaran dikarenakan untuk kelancaran lalu lintas 
kapal diperlukan adanya awak kapal yang memiliki keahlian, kemampuan dan terampil. Oleh karena itu, setiap kapal yang berlayar harus diawaki oleh awak kapal yang cukup dan cakap dalam menjalankan tugasnya di kapal sesuai jabatan dengan mempertimbangkan besaran kapal, tata susunan kapal dan daerah pelayaran (Malisan 2013).

\section{Kesejahteraan Awak Kapal dan Kesehatan Penumpang}

Salah satu penunjang peningkatan hasil produksi dipengaruhi oleh besarnya effort yang diberikan oleh nelayan, baik pada saat bekerja di atas kapal maupun pada saat persiapan sebelum berangkat melaut. Oleh karena itu, sudah seharusnya pemilik kapal memperhatikan kesejahteraan awak kapal dan kesehatan penumpang. Adapun kriteria aspek kesejahteraan kapal dan kesehatan penumpang. Skor aspek kesejahteraan kapal dan kesehatan penumpang menunjukkan bahwa kapal telah memenuhi kriteria kesejahteraan kapal dan kesehatan penumpang sebanyak 79,38\% sedangkan 20,62\% belum terpenuhi (Gambar 4).

Kriteria yang tidak dipenuhi oleh kapal yaitu kompensasi apabila kapal tidak dapat beroperasi karena mengalami kecelakaan. Hal ini dikarenakan armada yang berbasis di PPS Kutaraja merupakan usaha perseorangan hanya sebagian kecil yang merupakan usaha kelompok. Pendapatan yang diperoleh oleh pemilik kapal mutlak berasal dari penjualan hasil produksi jika kapal beroperasi. sehingga upah yang dibayar kepada ABK hanya jika kapal melakukan operasi. Selanjutnya terkait kesehatan nelayan, pihak syahbandar telah memberlakukan bahwa setiap kapal yang hendak beroperasi wajib membayar jaminan asuransi nelayan yaitu BPJS.

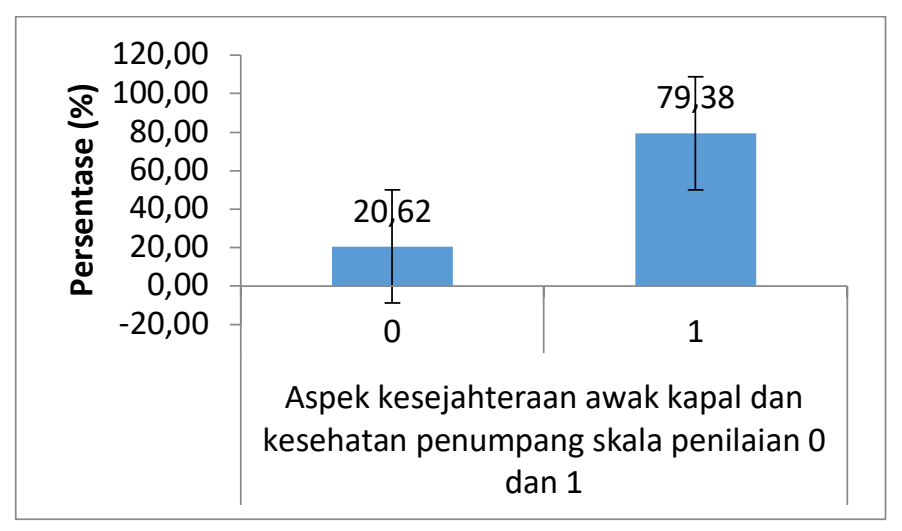

Gambar 4. Diagram skoring aspek kesejahteraan awak kapal dan kesehatan penumpang

Faktanya di lapangan, tidak semua pemilik kapal menanggung perawatan dan kesehatan ABK nya. 39 unit kapal tidak menanggung BPJS nelayan, pembayaran jaminan kesehatan mereka dibayar dari pemotongan gaji nelayan itu sendiri, sedangkan 49 kapal lainnya ditanggung oleh pemilik kapal tanpa pemotongan gaji.

\section{Status Hukum Kapal}

Sebanyak 82,39\% kapal yang berbasis di PPS Kutaraja telah memenuhi aspek status hukum kapal, hanya 17,61\% kapal yang belum memenuhi aspek status hukum kapal (Gambar 5). Kriteria aspek status hukum kapal yang belum terpenuhi artinya yang memperoleh nilai 0 (Tidak ada) yaitu pemasangan tanda selar, 41 kapal dari jumlah kapal sampel belum memasang tanda selar. Setiap kapal yang telah memperoleh surat ukur wajib memasang tanda selar secara permanen dibagian luar dinding depan bangunan atas atau pada tempat lain yang aman dan mudah dibaca sebagaimana yang diatur pada Undang-undang no 17 tahun 2008 tentang pelayaran. Hal ini perlu diperhatikan kembali oleh pihak PPS Kutaraja dalam melakukan pemeriksaan agar kapal yang berbasis di PPS Kutaraja memasang tanda selar secara menyeluruh. 


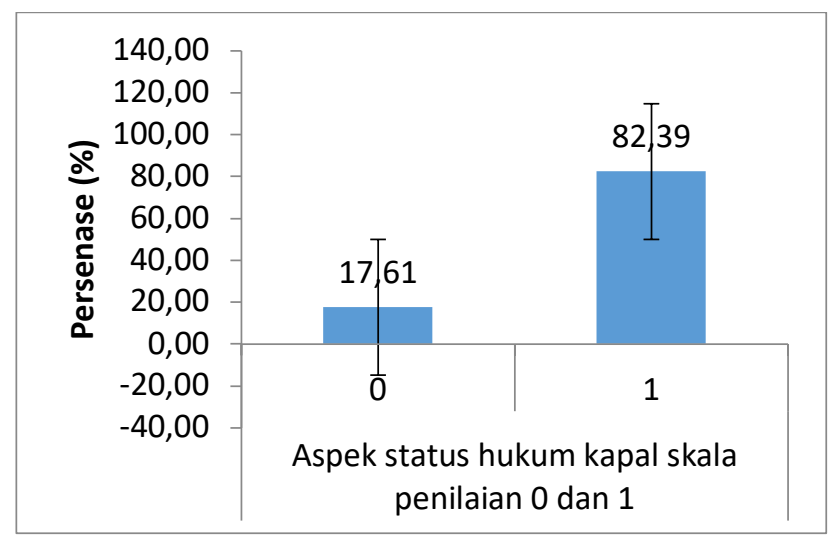

Gambar 5. Diagram skoring aspek status hukum kapal

Kapal yang tidak memasang tanda selar perlu dipertanyakan apakah sudah mengurus surat ukur kapal atau memang tidak memprioritaskan untuk memasang tanda selar. Ini juga merupakan bagian dari kedisiplinan pemilik kapal untuk mematuhi peraturan dalam memenuhi aspek status hukum kapal. Penerapan status hukum kapal ini bertujuan untuk menandakan asal usul kapal tersebut, jika suatu kapal mempunyai kebangsaan maka negaranya dapat membela kapal tersebut di forum international jika kapal tersebut mendapati suatu masalah (Tegoeh 2019). Penentuan status hukum kapal dilakukan setelah melalui proses pengukuran kapal, pendaftaran kapal, dan penetapan kebangsaan kapal.

\section{Manajemen Keselamatan dan Keamanan Kapal}

Skor penerapan aspek manajemen keselamatan dan keamanan kapal yaitu 57,27\% memperoleh nilai 1 (sangat baik), 38,64\% mendapat nilai 2 (baik), 3,54\% mendapat nilai 3 (buruk) dan 0,45\% memperoleh nilai 4 (sangat buruk) (Gambar 6a). Kriteria pengauditan, peninjauan ulang dan pengevaluasian yang dilakukan oleh perusahaan/pemilik kapal memperoleh skor yang bervariasi. Sejumlah 64 kapal memperoleh nilai 1(sangat baik) dan 2 kapal mendapat nilai 4 (sangat buruk). Kapal yang memperoleh nilai 3 (buruk) dan 4 (sangat buruk) dipastikan bahwa pemilik kapal sangat jarang melakukan pengauditan, peninjauan ulang dan pengevaluasian. Hal ini dikarenakan pemilik kapal bukan berasal dari wilayah Banda Aceh/Aceh besar, sehingga menyebabkan pemilik kapal jarang berkunjung. Namun, ini tidak menjadi masalah besar dikarenakan armada yang berbasis di PPS Kutaraja memiliki beberapa pengurus yang bertanggung jawab berdasarkan tugasnya, yaitu pengurus surat/dokumen kapal yang fokus pada pengurusan dokumen yang dibutuhkan oleh kapal dan bertugas melapor ke syahbandar baik sebelum berangkat maupun sesudah pulang melaut. Selanjutnya pengurus muatan kapal yaitu persiapan muatan logistik sebelum kapal melaut dan bertugas menjual hasil tangkapan.

Tanggung jawab lain yang berkaitan dengan fisik kapal dan ABK dipercayakan kepada nahkoda yang memiliki tanggung jawab penting dalam sebuah kapal. Tugas nahkoda ialah bertanggung jawab ketika mengoperasikan sebuah kapal dalam pelayaran dari pelabuhan satu menuju ke pelabuhan lainnya dengan selamat, tanggung jawab tersebut juga meliputi keselamatan kapal dan seluruh muatan yang ada didalamnya baik ABK maupun penumpang (Santosa 2019). Skoring aspek manajemen keselamatan kapal dan keamanan kapal berdasarkan skala penilaian 0 (tidak ada) dan 1 (ada) ialah $50 \%$ kriteria telah dipenuhi dan $50 \%$ belum terpenuhi (Gambar $6 \mathrm{~b}$ ). 


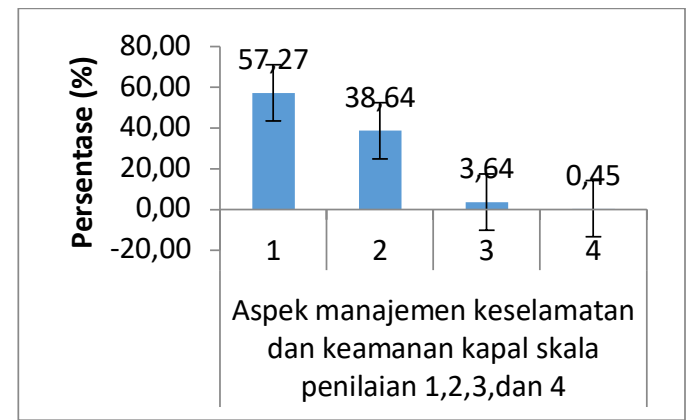

A

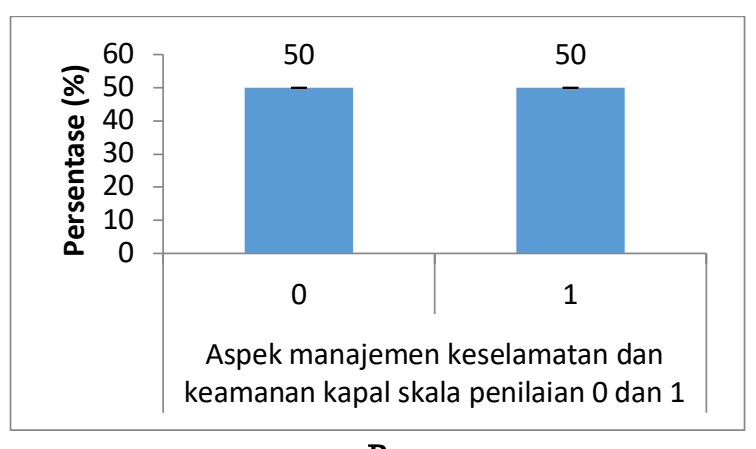

B

Gambar 6 (a) Skoring aspek manajemen keselamatan dan keamanan kapal (b) Skoring aspek manajemen keselamatan dan keamanan kapal

Pengadaan personil menjadi kriteria yang tidak diterapkan oleh kapal yang berbasis di PPS Kutaraja, disebabkan oleh kurangnya SDM dan juga untuk menunjuk personil darat khusus diperlukan pembayaran upah yang cukup besar sedangkan penghasilan dari akvitas kapal saja tidak menentu. Sedangkan kriteria pelaporan dan analisa atas ketidaksesuaian, kecelakaan dan kejadian bahaya telah diterapkan dengan baik oleh kapal yang berbasis di PPS Kutaraja.

\section{Kelengkapan Surat atau Dokumen Kapal}

Persentase surat/dokumen kapal yang telah dilengkapi oleh kapal yaitu sebanyak 59,09\% dan belum dilengkapi sebanyak 40,91\% (Tabel 2). Terdapat beberapa surat/dokumen yang tidak diwajibkan oleh syahbandar untuk dimiliki oleh kapal yang berbasis di PPS Kutaraja, yaitu sertifikat pencegahan dan pengendalian pencemaran, sertifikat manajemen keselamatan, sertifikat manajemen keamanan kapal, dan sertifikat keselamatan. Kebijakan ini dibuat oleh pihak pelabuhan dikarenakan beberapa pertimbangan seperti PPS Kutaraja masih dalam tahap pengembangan sehingga pihak syahbandar tidak mewajibkan beberapa dokumen kapal seperti yang tersebut dalam UU no 17 tahun 2008, jumlah kapal besar ( $>60$ GT) masih sedikit dan peralatan di atas kapal masih belum modern seperti tidak adanya fasilitas penampungan limbah serta penghancur sampah dikarenakan aktivitas kapal yang berbasis di PPS Kutaraja masih manual. Namun, pihak syahbandar tetap berupaya agar kedepannya seluruh dokumen/surat kapal dapat dilengkapi oleh pemilik kapal sebagaimana yang tertera pada undang-undang no 17 tahun 2008.

Surat/dokumen yang wajib dilengkapi oleh kapal yang berbasis di PPS Kutaraja, yaitu sertifikat kelayakan dan pengawakan kapal penangkap ikan, surat keterangan kecakapan nahkoda, surat kecakapan masinis, surat ukur kapal, pemasangan tanda selar, gross akta pendaftaran kapal, pas besar/pas kecil, surat izin penangkapan ikan (SIPI), dan surat izin usaha perikanan (SIUP). Berdasarkan semua jenis dokumen yang wajib dipenuhi oleh kapal yang berbasis di PPS Kutarja, beberapa dokumen yang tidak dilengkapi yaitu salah satunya pemasangan tanda selar yang mendapat nilai 0 (tidak ada) terbanyak, yaitu 36 unit kapal dari total kapal sampel tidak memasang tanda selar. Alasan tidak lengkapnya beberapa dokumen tersebut ialah karena sedang dalam pengurusan (baik karena dokumen tersebut hilang, rusak, dan sedang dalam masa perpanjangan). Jika surat/dokumen kapal sedang dalam perpanjangan masa berlaku., maka syahbandar akan mengeluarkan surat keterangan agar kapal tersebut tetap melaut dengan mengikuti syarat dan ketentuan yang berlaku. Kelengkapan dokumen tersebut penting untuk dipersiapkan agar kapal mendapat surat persetujuan berlayar (SPB) yang dikeluarkan oleh Syahbandar.

SPB merupakan salah satu dokumen penting yang menjadi penentu apakah sebuah kapal (angkatan laut) dapat melakukan pelayaran atau tidak (Badaruddin et al. 2021). Penerbitan surat persetujuan berlayar diberikan kepada kapal setelah pemilik kapal melakukan serangkaian mekanisme pengurusan yang meliputi pengajuan permohonan penerbitan surat persetujuan berlayar 
secara tertulis kepada syahbandar dengan melampirkan: surat pernyataan nahkoda, pembayaran BPJS dan dokumen muatan serta bukti-bukti pemenuhan kewajiban kapal lainnya.

Tabel 2. Skoring kelengkapan surat/dokumen kapal

\begin{tabular}{|c|c|c|c|}
\hline \multirow{2}{*}{ Kelengkapan Surat/Dokumen Kapal } & \multicolumn{2}{|c|}{ Skoring } & \multirow{2}{*}{ Total } \\
\hline & 0 & 1 & \\
\hline Sertifikat kelayakan dan pengawakan kapal penangkap ikan & & 88 & 88 \\
\hline Sertifikat pencegahan dan pengendalian pencemaran & 88 & & 88 \\
\hline Surat Keterangan Kecakapan Nahkoda & 3 & 85 & 88 \\
\hline Surat Keterangan Kecakapan Masinis & 14 & 74 & 88 \\
\hline Surat ukur kapal & 11 & 77 & 88 \\
\hline Pemasangan tanda selar & 36 & 52 & 88 \\
\hline Gross akta pendaftaran kapal/BPKP & 17 & 71 & 88 \\
\hline Pas besar/pas kecil & 3 & 85 & 88 \\
\hline Sertifikat manajemen keselamatan & 88 & & 88 \\
\hline Sertifikat manajemen keamanan kapal & 88 & & 88 \\
\hline Sertifikat keselamatan & 88 & & 88 \\
\hline Surat Izin Penangkapan Ikan & 18 & 70 & 88 \\
\hline Surat Izin Usaha Perikanan & 14 & 74 & 88 \\
\hline Total & 468 & 676 & 1144 \\
\hline Persentase & 40.91 & 59.09 & 100 \\
\hline Rata-rata & 39 & 75.11111 & \\
\hline
\end{tabular}

Sumber: Pengolahan Data

Pemenuhan kewajiban kapal yang dimaksud di atas berupa bukti pembayaran jasa kepelabuhanan, bukti pembayaran BPJS anggota nelayan, dan pelaporan E-logbook. Pejabat kesyahbandaran melakukan verifikasi/pemeriksaan sertifikat dan dokumen kapal, jika kapal telah memenuhi kriteria persyaratan maka pihak kesyahbandaran akan mengeluarkan surat persetujuan berlayar. Sebelum pemberian surat persetujuan berlayar seorang syahbandar harus memastikan bahwa kapal yang akan berlayar harus memenuhi beberapa unsur-unsur penting demi terlaksananya fungsi keselamatan dan keamanan pelayaran.

Salah satu unsur penting selain verifikasi dokumen, pihak kesyahbandaran juga perlu melakukan pengecekan fisik kapal sebelum melaut untuk melihat apakah benar kapal tersebut telah memenuhi aspek laik laut. Namun, pengecekan fiisk kapal oleh pihak kesyahbandaran hanya dilakukan 1 tahun sekali dikarenakan SDM terbatas sehingga tidak memungkinkan untuk mengecek fisik setiap kapal yang akan melaut. Hal ini tentu berdampak buruk terhadap kedisiplinan nelayan dalam memenuhi alat keselamatan, alat kenavigasian, dan kesesuaian jumlah ABK dengan crew list yang mereka daftarkan.

Oleh karena itu, mayoritas dari kapal-kapal yang telah dilakukan wawancara tidak memiliki alat keselamatan yang layak dan tidak ditempatkan sesuai dengan fungsinya. Pelampung yang disediakan oleh pemilik kapal terkadang tidak sesuai dengan crew list, bahkan beberapa kapal menjadikan jerigen sebagai pelampung. Selain itu, penempatan pelampung berada dibawah dek yaitu diruang mesin sehingga tidak mudah dijangkau jika terjadi kecelakaan seperti kapal tenggelam maupun nelayan tercebur kelaut. Ini menjadi tanggung jawab pihak kesyahbandaran dalam mengawasi armada kapal yang berbasis di pelabuhannya masing-masing.

\section{Tingkat Implementasi Kelaiklautan Kapal pada Armada yang Berbasis di PPS Kutaraja}

Penyelenggaran kelaiklautan kapal merupakan salah satu wujud dari pelayanan pemerintah dalam menunjang keselamatan pelayaran. Keselamatan pelayaran erat kaitannya dengan penerapan 
aspek kelaiklautan kapal, sebagaimana hasil penelitian (Mudiyanto 2019) menjelaskan bahwa berdasarkan hasil pengolahan data koefisien korelasi berganda dapat ditunjukkan bahwa antara variabel kelaiklautan kapal memiliki hubungan yang kuat terhadap variabel keselamatan pelayaran. Jika skala penilaian 1,2,3 dan 4 (Tabel 3) berfungsi untuk menggambarkan bagaimana penilaian terhadap penerapan setiap aspek kelaiklautannya.

Skala penilaian 0 dan 1 menjadi patokan untuk melihat apakah kriteria setiap aspeknya telah terpenuhi (1) atau tidak terpenuhi (0) (Tabel 4). Perbedaan penggunaan skala penilaian ini dilakukan untuk menyesuaikan pertanyaan pada setiap kriteria, kriteria yang membutuhkan jawaban apakah diterapkan atau tidak akan dimasukkan ke dalam kategori skala penilaian 0 (tidak ada) dan 1 (ada). Sedangkan kriteria yang membutuhkan penilaian dalam penerapannya maka akan dimasukkan ke dalam kategori skala penilaian 1 (sangat baik), 2 (baik), 3 (buruk) dan 4 (sangat buruk).

Tabel 3. Penilaian aspek kelaiklautan kapal skala penilaian 1, 2, 3 dan 4

\begin{tabular}{lrrrrr}
\hline \multirow{2}{*}{ Aspek kelaiklautan kapal } & \multicolumn{4}{c}{ Skala Penilaian } & \multirow{2}{*}{ Total (\%) } \\
\cline { 2 - 5 } & 1 & 2 & 3 & 4 & \\
\hline Aspek Keselamatan & 43.32 & 32.67 & 16.48 & 7.53 & 100.00 \\
Aspek Pencegahan Pencemaran & 0.19 & 1.32 & 0.19 & 98.31 & 100.00 \\
Aspek pengawakan kapal & 16.67 & 65.15 & 17.80 & 0.38 & 100.00 \\
Aspek manajemen keselamatan kapal & 57.27 & 38.64 & 3.64 & 0.45 & 100.00 \\
\hline
\end{tabular}

Sumber: Pengolahan Data

Tabel 4. Penilaian aspek kelaiklautan kapal skala penilaan 0 dan 1

\begin{tabular}{lrrl}
\hline \multirow{2}{*}{ Aspek Kelaiklautan Kapal } & \multicolumn{2}{c}{ Skala Penilaian } & \multirow{2}{*}{ Total } \\
\cline { 2 - 3 } & \multicolumn{1}{c}{ (\%) } \\
\hline Aspek keselamatan & 14.26 & 85.74 & 100.00 \\
Aspek pengawakan kapal & 0 & 100 & 100.00 \\
Aspek Kesejahteraan awak kapal & 20.62 & 79.38 & 100.00 \\
Aspek status hukum kapal & 17.61 & 82.39 & 100.00 \\
Aspek manajemen keselamatan kapal & 50 & 50 & 100.00 \\
Aspek kelengkapan surat & 40.91 & 59.09 & 100.00 \\
\hline
\end{tabular}

Sumber: Pengolahan Data

Hasil skoring tingkat implementasi aspek kelaiklautan kapal pada armada yang berbasis di PPS Kutaraja dapat dilihat pada Tabel 3 dan 4. Aspek keselamatan dengan perolehan nilai 1 (sangat baik) sebanyak 43,32 \%, hanya 7,53\% yang memperoleh nilai 4 (sangat buruk) dan $85,74 \%$ mendapat nilai 1 (ada). Selanjutanya, aspek manajemen keselamatan memperoleh skor 57, 27\% yang mendapat nilai 1 (sangat baik), hanya 0,45\% yang mendapat nilai 4 (sangat buruk) dan 50\% mendapat nilai 1 (ada). Hal ini mengindikasikan bahwa PPS Kutaraja telah memiliki titik terang dalam penerapan aspek manajemen keselamatan kapal serta aspek keselamatan dan keamanan kapal.

Meskipun masih belum optimal dalam penerapannya, namun hal ini menjadi langkah awal bagi pihak syahbandar agar dapat mengoptimalkan aspek tersebut sehingga tepat dalam penerapannya. Aspek pengawakan kapal memeproleh nilai 1 (sangat baik) sebanyak 16,67\%, sebanyak 65,15\% mendapatkan nilai 2 (baik), hanya 0,38\% yang memeperoleh nilai 4 (sangat buruk) dan 100\% memperoleh nilai 1 (ada). Maka dapat dikatakan bahwa tanggung jawab nahkoda layak mendapat apresiasi dalam mewujudkan aspek pengawakan yang optimal.

Aspek kesejahteraan awak kapal dan kesehatan penumpang memperoleh skor 79,38\% yang mendapat nilai 1 (ada) dan 20,62\% memperoleh nilai 0 (tidak ada). Aspek status hukum kapal memperoleh skor 82,39\% yang mendapat nilai 1 (ada) dan 17,61 mendapat nilai 0 (tidak ada). Aspek pencegahan pencemaran perairan dari kapal memperoleh skor 0,19\% mendapat nilai 1 (sangat baik) 
dan sebanyak 98,31\% memperoleh nilai 4 (sangat buruk). Informasi yang diperoleh dari wawancara, nelayan yang berbasis di PPS Kutaraja sangat awam terkait mekanisme pencegahan pencemaran perairan dari kapal. Hal ini dipengaruhi oleh tidak adanya kepedulian nelayan terhadap lingkungan perairan dan lingkungan pelabuhan. Hal ini juga erat kaitannya dengan kurangnya sosialisasi terkait pencegahan pencemaran perairan dari kapal. Jika hal ini disepelekan, akan berdampak buruk terhadap lingkungan.

Melihat banyaknya aktivitas kapal yang melakukan berbagai aktiviitas baik di pelabuhan dan perairan, maka dampak terhadap kerusakan lingkungan akan lebih cepat terjadi. Hal ini perlu dievaluasi secepatnya dan dicarikan solusinya. Aspek kelengkapan surat/dokumen kapal memperoleh skor 59,09\% mendapat nilai 1 (ada) dan 40,9\% mendapat nilai 0 (tidak ada).

\section{KESIMPULAN DAN SARAN}

Perolehan skor tingkat implementasi aspek kelaiklautan kapal yang memperoleh nilai tertinggi ke terendah dalam penerapannya di PPS Kutaraja ialah aspek pengawakan kapal, dengan perolehan skor $100 \%$ dan 65,15\% ; aspek keselamatan dan keamanan kapal 85,74\% dan 43,32\%; aspek status hukum kapal 82,39\%; aspek kesejahteraan awak kapal dan kesehatan penumpang 79,38\%; aspek manajemen keselamatan kapal 50\% dan 57,27\%; dan kelengkapan surat/dokumen kapal 40,9\%. Implementasi aspek kelaiklautan kapal yang memperoleh skor terburuk dalam penerapannya di PPS Kutaraja ialah penerapan aspek pencegahan pencemaran perairan dari kapal, dengan perolehan skor $98,31 \%$ mendapat nilai 4 (sangat buruk).

\section{DAFTAR PUSTAKA}

Badaruddin, Renggong R, Hamid A H. 2021. Analisis Tanggung Jawab Hukum Nahkoda Terhadap Keselamatan Pelayaran di Wilayah Kesyahbandaran Utama Makassar. Indonesian Journal of Legality of Law 3(2): 84.

BASARNAS Aceh. 2019. Rekapitulasi Kecelakaan 2019. Aceh: Laporan Basarnas Provinsi Aceh.

Buku Statistik Tangkap. 2019. Buku Statistik Tangkap 2019. Aceh: Badan Pusat Statistik Provinsi Aceh.

FAO. 2020. The State of World Fisheries and Aquaculture-Sustainability in Action. Rome. Italy.

ILO. 2019. Work for A Brighter Future: Global Commission on The Future of Work. International Labour Office. Geneva. Switzerland.

Komite Nasional Keselamatan Transportasi. 2019. Data Investigasi Kecelakaan Pelayaran KNKT 2015-2019. Media Release KNKT Tahun 2019. Jakarta.

Malisan J. 2013. Kajian Pengawalan Kapal Tonase Kurang dari GT 7 pada Wilayah Perairan Pedalaman dalam Meningkatkan Keselamatam Pelayaran "Studi Kasus: Sampit". Warta Penelitian Perhubungan 25(1): 2.

Murdiyanto. 2019. Analisis Kelaiklautan Kapal Terhadap Keselamatan Pelayaran Di Kapal Niaga (Studi Kasus Pada Perusahaan Pelayaran Kapal Penumpang Di Surabaya). Jurnal Saintek Maritim. 20(1): 26.

Nasution R. 2013. Teknik Sampling. Sumatra Barat: Perpustakaan Digital USU.

Nur I. 2015. Faktor-Faktor yang Mempengaruhi Beban Rancangan (Design Load) terkait dengan Perhitungan Kontruksi Kapal-Kapal Niaga Berbahan Baja Menurut Regulasi Klas. Bina Teknika 11(2): 198-204. 
Rahman H, Satria A, Iskandar BH, Soeboer DA. 2017. Penentuan Faktor Dominan Penyebab Kecelakaan Kapal di Kesyahbandaran Utama Tanjung Priok. Albacore 1(3): 277-284.

Riduwan dan Kuncoro EA. 2011. Cara Menggunakan dan Memaknai Analisis Jalur (Path Analysis). Cetakan Ketiga. Bandung: Alfabeta.

Santosa A dan Sinaga EA. 2019. Peran Tanggung Jawab Nahkoda dan Syahbandar Terhadap Keselamatan Pelayaran Melalui Pemanfaatan Sarana Bantu Navigasi di Pelabuhan Tanjung Emas Semarang. Jurnal Saintek Maritim 20(1): 30.

Sugiyono. 2011. Metode Penelitian Kuantitatif Kualitatif dan R\&D. Bandung: Alfabeta.

Suwardjo D, Haluan J, Indra J, Poernomo HS. 2010. Kajian Tingkat Kecelakaan Fatal, Pencegahan dan Mitigasi Kecelakaan Kapal- Kapal Penangkap Ikan yang Berbasis Operasi di PPP Tegalsari, PPN Pekalongan dan PPS Cilacap. MARITEK 10(1): 61-72.

Tegoeh HF. 2019. Pemberian Status Hukum Terhadap Kapal yang Berkebangsaan Indonesia. Justicia Sains: Jurnal Ilmu Hukum 4(2): 122.

[UU] Undang- Undang Republik Indonesia. 2008. Undang-undang Republik Indonesia No 17 Tahun 2008 Tentang Pelayaran. Jakarta: Presiden Republik Indonesia.

Wahab AR. 2014. Penggunaan Alat dan Perangkat Telekomunikasi dalam Sistem Navigasi dan Komunikasi Aktivitas Perikanan di Pelabuhan Perikanan Bitung. Buletin Pos dan Telekomunikasi 12(4): 279-290. 